\title{
Factors Affecting the Capacity of Small to Medium Enterprises (SME) Building Construction Firms in Ghana
}

\author{
Isaac Offei , , Ernest Kissi ${ }^{2}$ and Gabriel Nani²
}

\begin{abstract}
Published online: 30 August 2019
To cite this article: Isaac Offei, Ernest Kissi and Gabriel Nani (2019). Factors affecting the capacity of small to medium enterprises (SME) building construction firms in Ghana. Journal of Construction in Developing Countries, 24(1): 49-63. https://doi.org/10.21315/jcdc2019.24.1.3.
\end{abstract}

To link to this article: https://doi.org/10.21315/jcdc2019.24.1.3

\begin{abstract}
There is a raft of factors that affect the capacity of local construction firms in Ghana, particularly those in the smaller contractor classifications. These factors render small to medium enterprises (SME) ineffective in administration of construction processes. As a result, these firms are not able to match with growing demands of stakeholders and end up collapsing. In this article, factors affecting the capacity of SME building construction firms in Ghana were empirically ascertained. This involved a review of published research works on the construction industry, generally in both developed and developing countries focusing on Ghana. Both qualitative and quantitative research methods were employed while conducting the study. The data obtained during the research were analysed using descriptive statistics and factor analysis. It emerged from the study, among other factors, the following as key factors affecting the financial, managerial and technical capacities of SME construction firms in Ghana: delay in payment for work done, limited access to finance, non-payment of interest on delayed payments and lack of fair competition. It is therefore recommended that if there is any policy that is directed at building the capacity of the SME Construction firms in Ghana, it should endeavour to mitigate the aforementioned factors.
\end{abstract}

Keywords: Capacity, Developing countries, Ghana, SME building contractors

\section{INTRODUCTION}

One of the major components of government's expenditure since Ghana gained her independence in 1957 is construction works as the government spends a lot of money in the provision of infrastructure in the various sectors of the country (AmpaduAsiamah and Ampadu-Asiamah, 2013). This is because the physical infrastructure, built through the various construction activities, is the nation's economic backbone. It forms the arteries for the facilitation of productive activities by enabling goods and services to be distributed within and outside the country (Ofori, 2012). This explains why the bulk of the expenditure programmes of ministries, departments, agencies (MDAs) and district assemblies (DAs) of the Republic of Ghana involve procurement of construction products (Anvuur, Kumaraswamy and Male, 2006). It must however be noted that exploiting the activities and outcomes of the Ghanaian construction industry (GCl) towards an anticipated socio-economic progress cannot be predicated upon a fragile developmental framework and illequipped industry (Badu and Owusu-Manu, 2010; Ahadzie, 2009). Thus, the capacity

\footnotetext{
'Takoradi Technical University, Department of Building Technology, Takoradi, GHANA

${ }^{2}$ Department of Construction Technology and Management Kwame Nkrumah University of Science and Technology, Kumasi, GHANA

"Corresponding author: kisernest@yahoo.com
} 
of the local construction firms in the $\mathrm{GCl}$ needs to be strengthened enough to enable them serve the necessary demand for construction products.

In Ghana, both building and civil engineering contractors are respectively classified under categories D1, D2, D3, D4 and K1, K2, K3, K4 by the Ministry of Water Resources, Works and Housing in collaboration with the Registrar General's Department (Amoah, Ahadzie and Danso, 2011 ; Agyepong, 2012). This classification is done with reference to factors such as annual turnover, equipment holding and personnel. Thus, the DIKI class of contractors are regarded as larger firms, whereas D2K2 construction firms are medium, and D3K3 and D4K4 are small firms (cf. Danso, 2010; Amoah et al., 2011). By this classification, firms in each category could tender for building contracts within a certain financial threshold (Badu, Edwards and Owusu-Manu, 2012). In the context of this study, small to medium enterprises (SME) building contractors (SMEBCs) refer to firms within D4K4, D3K3 and D2K2 categories. A lot of studies have been conducted in Ghana that have identified and proposed solutions for the challenges that face the construction industry (Ahadzie, 2009; Badu and Owusu-Manu, 2010; Laryea, 2010; Danso, 2010; Amoah, Ahadzie and Danso, 2011). Notwithstanding, most of the writers have largely focused on relatively larger construction firms than the smaller construction firms (even though, the small-scale construction firms constitute a larger proportion of the number of firms in the construction industry) (Amoah, Ahadzie and Danso, 2011 ). Research has it that $90 \%$ of registered contractors belong to the lower classes in Ghana (van Egmond and Erkelens, 2007). Regardless of the sizes of these SME building construction firms, they collectively contribute significantly to the overall construction gross domestic product (GDP), especially in the development of decentralised and local government areas (Amoah, Ahadzie and Danso, 2011). However, in spite of the significance of the construction industry, with regard to national socio-economic development, construction firms, particularly those that belong to the SME categories are faced with a raft of challenges that affect their capacity (Anaman and Osei-Amponsah, 2007; Amoah, Ahadzie and Danso, 2011). These challenges that face the Ghanaian construction industry in general and the SMEBCs firms in particular go to affect their competitiveness and their survival in business. It is therefore imperative to empirically ascertain the key factors affecting the capacity of SME building construction firms. The term capacity is used in several contexts with deferent meanings, depending on the message that is sought to be conveyed (Morgan, 2006; Enemark, 2003). The Oxford Advanced Learner's Dictionary defines capacity as "the ability to understand or do something". The United Nations Educational, Scientific and Cultural Organization (UNESCO) (2006) however makes the definition much broader. It thus defines capacity as the ability of individuals, organisations, or systems to perform appropriate functions effectively, efficiently and sustainably. Indeed, the term capacity can be related to the abilities, skills, knowledge, learning attitudes, values, relationships, behaviours, motivations, resources and conditions that enable individuals, organisations, institutions and systems to carry out functions effectively, efficiently and innovatively in order to achieve their development objectives (Kululanga, 2012). Therefore, for the purposes of this article, capacity will be referred to as the technical knowhow, managerial skills and financial strength that are required by a firm in order to meet its client's demand effectively and efficiently. To meet this objective, the capacity of construction firms and the factors that affect their capacity are generally reviewed based on findings from previous studies and other literature information. The research methodology 
was then designed by taking a cue from the methods of data collection, analysis and inferences from literature of similar studies.

\section{FACTORS AFFECTING THE CAPACITY OF SME BUILDING CONSTRUCTION FIRMS}

Regardless of the acknowledged significant contributions small construction firms make to the economy in terms of employment, the challenges faced by these firms can be overwhelming (Amoah, Ahadzie and Danso, 2011). A study conducted by Donkor (2011) reveals that the determinants of business failure in the perspective of SMEBCs in the Ghanaian construction industry are suspension of projects of previous government, delay in collecting debts from new political heads, financial demands from political heads, non-payment of interest on delayed payments, assigning incompetent project leader at the site, lack of access to capital, undervaluing of work done, change in government policies, low profit margin due to competition and delay in collecting payments. Others include frauds/pilfering, lack of material control systems, poor monitoring and control, poor estimation practices, awarding contracts to incompetent political party members, poor tendering/selection procedure, high and unstable inflation and national slump in the economy.

In a related study that sought to find the factors that affect the performance of small construction firms in Ghana, Amoah, Ahadzie and Danso (2011) empirically revealed that the factors can be grouped under fiscal policies and managerial capacity. In that study, it was revealed from literature that chronic delay in the payments of contractors for work done, lack of credit facilities for firms, poor communication structures and an unreliable material supply base are some of the factors that can affect the performance of small building contractors in Ghana. That notwithstanding, the productivity of SMEBCs has been shown to be hampered by laid down procedures, delayed payments and resource constraints (Kheni, 2008). Besides, Kheni asserts that stiff competition that is faced by these SMEs go a long way to hamper their growth and hence their capacity. Research has shown that delay in payment has been identified as the severest factor constraining the finances of contractors (Eyiah, 2003), hence, their financial capacity. In South Africa, another African country such as Ghana, accesses to markets, credit, skills and supportive institutional arrangements have been identified as the basic constraints to the development in the small business sector (Govender and Watermeyer, 2000).

Bakar et al. (2012) also identified factors of management and product quality, human factor and customer orientation as the most significant factors that affect the turnover growth for construction companies. It has been reviewed in literature that about three decades ago, chronic delay in the payments of contractors for work done, lack of credit facilities for firms, poor communication structures and an unreliable material supply base, technical capabilities, high inflation rates are potential factors that can affect the capacity of small scale building contractors (Eyiah and Cook, 2003; Amoah, Ahadzie and Danso, 2011). Indeed, Cook and Nixson (2000) assert that most surveys have identified a plethora of factors that inhibit the capacity of smaller firms to include access to finance, poor managerial skills, lack of training opportunities and the high cost of inputs. Laryea (2010) asserts that contractors in the small and medium bracket in most developing countries have limited access to funding sources which prevents them from satisfying the financial requirements (e.g. bid and performance bonds) needed to win major contracts often awarded to their foreign counterparts. 
It has been noted that high tendering costs worsens the plight of SMEBCs in that several criteria must be met in order for a tender to be compliant with bidding requirements. This compels owner/managers to develop strong friendship networks as tools for dealing with state bureaucracy (Kheni, 2008). Kheni stresses this point by revealing that the average number of documents required in order for a contractor to submit a tender that meets bidding requirements is in the Region of 15 to 25 . Indeed, competitive tendering, as contained in the Public Procurement Act 2003 (Act 663), has become the usual way of procuring physical development projects in the public sector because of requirements of transparency and accountability in the management of public finance (Anvuur, Kumaraswamy and Male, 2006). This is likely to result in under-pricing by many SMEs in a bid to win contracts and subsequently not performing upon award of a public contract (Kheni, 2008). Research has also revealed that delays with interim and final payments, as well as onerous contract conditions faced by construction firms, can also impose a very significant challenge on the SME building contractors (Thwala and Phaladi, 2009). Thwala and Phaladi (2009) in their findings reveal that lack of financial management, lack of entrepreneurial skills, lack of proper training, lack of resources, lack of technical skills, lack of contractual and managerial skills, late payment for work done which are common with government contracts, inability to get credit from suppliers and fronting for established contractors are also contributing factors for the failure of emerging contractors in South Africa, a developing country such as Ghana.

It must be noted that the various factors that affect the capacity of the SMEBCs are not in isolation as each one of them may directly or indirectly lead to another. For instance, financial constraints impact upon the firms in satisfying plant and equipment capacity (Egbu, 2000; Thwala and Phaladi, 2009). Indeed, building the capacity of SMEs has become a concern of many developing countries including Ghana (Komu, Kikwasi and Thwala, 2012). This is at the wake of acknowledging that the capacity challenges of SMEBCs need to be addressed by the various stakeholders and governments collectively (Amoah, Ahadzie and Danso, 2011; Komu, Kikwasi and Thwala, 2012). In summary, the following have been identified by Donkor (2011), Kheni (2008), Eyiah (2003), Laryea (2010), Cook and Nixson (2000), Thwala and Phaladi (2009), Eyiah and Cook (2003) and Amoah, Ahadzie and Danso (2011), as the most significant factors that influences and in most cases, hinders the development of small scale contractors:

1. Suspension of projects of previous government,

2. Delayed payments/delay in collecting debts from new political heads,

3. Financial demands from political heads,

4. Non-payment of interest on delayed payments,

5. Assigning incompetent project leader at the site,

6. Lack of access to capital/problematic or limited access to finance,

7. Undervaluing of work done,

8. Change in government policies,

9. Low profit margin due to competition,

10. Frauds/pilfering,

11. Lack of material control systems,

12. Poor monitoring and control,

13. Poor estimation practices,

14. Awarding contracts to incompetent political party members,

15. Poor tendering/selection procedure/long laid down procurement procedures/ 
competitive tendering,

16. High and unstable inflation,

17. Delayed payments and resource constraints,

18. High tendering costs,

19. Poor managerial skills,

20. Lack of training opportunities,

21. High cost of inputs,

22. Onerous contract conditions,

23. Lack of financial management,

24. Lack of entrepreneurial skills,

25. Lack of proper training,

26. Lack of resources,

27. Lack of technical skills,

28. Lack of contractual skills,

29. Fronting for established contractors,

30. Lack of credit facilities for firms,

31. Poor communication structures and

32. Unreliable material supply base.

\section{RESEARCH METHODOLOGY}

Employing both qualitative and quantitative methods, the empirical investigation was conducted using structured interviews and survey questionnaires. The interviews were conducted prior to the survey to elicit in-depth information about the factors affecting the capacity of SME building construction firms in Ghana. Using purposive sampling technique, 10 respondents were selected for the semi-structured interview. The obtained data was analysed using qualitative data analyses software, Nvivo 8.0, which enabled the establishment of relevant constructs from the data. This led to the identification of the key areas that SMEBCs in Ghana and other factors which were not mentioned in literature. These factors were later evaluated using survey questionnaires. In designing the questionnaires, efforts were made to ask questions, considering the background of respondents in order to generate understanding and interest and also the analytical tool to be employed in the data analysis. The questionnaires were distributed to construction industry professionals (quantity surveyors, project managers and procurement managers) in Ghana working with public client organisations, consultancy firms and contractors (D2K2, D3K3 and D4K4). These respondents were asked to rank on a scale of 1 = "Least" to 5 = "Highest". The significance of the various factors that affect the (identified from both literature and the semi-structured interview) capacity of SMEBCs in Ghana. The distribution of questionnaires was done using snowball sampling technique, due to the difficulty in identifying the various respondents, particularly, active SMEBCs in the country. Thus, a total of 125 questionnaires were administered to various respondents. However, 80 questionnaires were retrieved and were useable for analysis purposes, representing $64 \%$ response rate. One sample t-test with a test value of 3.0 was used to ascertain, whether or not the mean rating of a given variable is significantly different from the hypothetical mean, $\mu=3.0$ (Ayarkwa, Dansoh and Amoah, 2010). The factors that did not meet the test criterion were discarded whereas those that met the test criterion were considered for further analysis. 


\section{ANALYSIS AND RESULTS}

As it has been stated earlier, the research used both semi-structured interviews and survey questionnaires to elicit information from the various respondents. The factors presented in Table 1 are the additional factors that were obtained from interviews that were conducted. These factors were compared to those that were earlier obtained from the literature survey to avoid repetition and to add onto the list of unique factors. The factors were subsequently presented in the questionnaire survey for evaluation by a larger respondent group. This was for the purposes of establishing the significant factors affecting the capacity of SMEBCs in Ghana.

\section{Key Areas Which SMEBCs in Ghana Lack Capacity}

Literature has revealed that the capacity of contractors in Ghana is generally low and this has been the reason why most major public contracts are awarded to the few foreign construction firms that are operating in the country (Ahiaga-Dagbui et al., 2011; Amoah, Ahadzie and Danso, 2011; Badu and Owusu-Manu, 2010; Fugar and Agyakwah-Baah, 2010; Laryea, 2010). This assertion is a general reflection of the situation among the various developing countries (Gyadu-Asiedu, 2009). Indeed, the capacity of building contractors in Ghana is lacking in several areas. In a response to the question of the areas in which SMEBCs in Ghana lack capacity, a respondent put it as "almost everything; they don't have plants...even the technical expertise they don't have...even their financial levels too... so I think they lack almost everything...".

According to the various interviewees, most of the contractors in the country, particularly those in the SME categories lack capacity in the areas of financial, technical, managerial and plants, and equipment levels. One of the interviewees asserted that the various areas that the contractors lack capacity are interrelated in that one may lead to another. This is consistent with an assertion revealed in literature (Egbu, 2000; Thwala and Phaladi, 2009). Figure 1 illustrates the various areas that SMEBCs in Ghana lack capacity as explained by the various respondents.

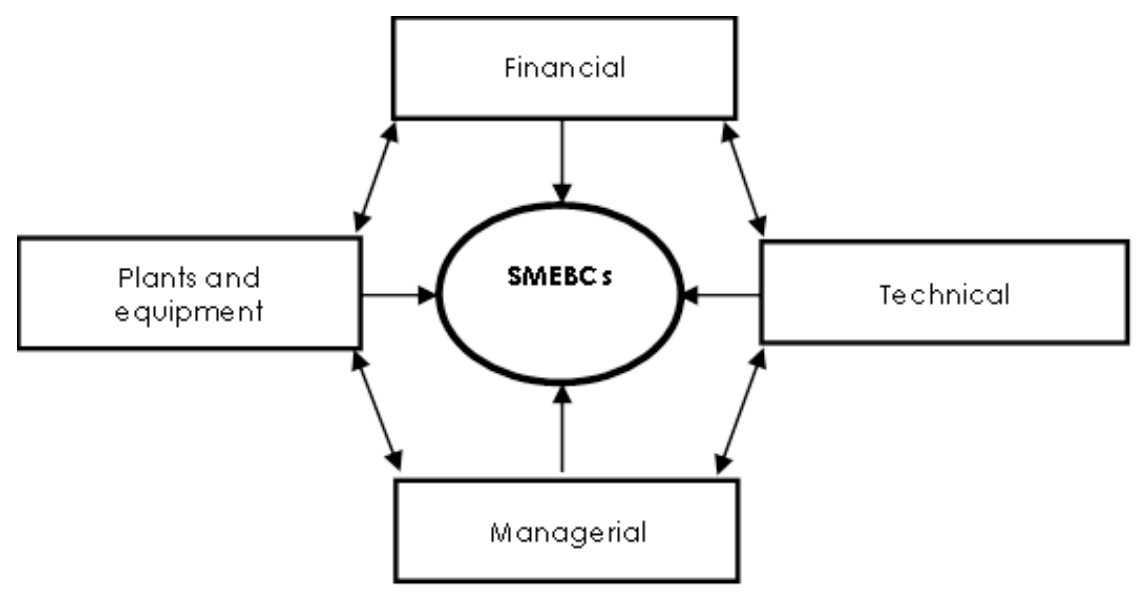

Figure 1. Key Areas that SMEBCs in Ghana Lack Capacity 
As it has been explained, the various areas that SMEBCs lack capacity are interrelated. From Figure 1, the double arrows illustrate these interrelationships between the various areas. However, the single arrows show that all the four areas are lacking by SMEBCs. For instance, if a contractor is financially constrained, it will be difficult for him to purchase the requisite plant and equipment in order to execute his jobs effectively. The four areas (financial, managerial, plant and equipment and technical) have been ascertained as the key areas that SMEBCs lack capacity in Ghana and for these construction firms to continue to be relevant in the socioeconomic development of the nation, these areas need to be addressed. Indeed, for these capacities to be built, much effort is required from the contractors themselves and the state (that is, providing an enabling environment by putting certain policies and strategies in place).

In Table 1, the various factors which were obtained from the semi-structured interview that was conducted have been presented. These factors were added up to those factors which were obtained from the literature review for the design of the questionnaires which made it possible for broader opinions to be elicited from a larger number of respondents. The data that was obtained from the questionnaire survey has firstly analysed using mean score ranking (as shown in Table 2).

Table 1. Additional Factors obtained from Semi-Structured Interview/s Respondents

\begin{tabular}{cl}
\hline No. & Factors Affecting the Capacity of SMEBCs in Ghana \\
\hline 1. & Structure of the companies \\
2. & Lack of fair competition \\
3. & Lack of understanding of the procurement processes \\
4. & Lack of mobilisation \\
5. & Lack of qualified personnel \\
6. & Non-business-like style of contractors \\
7. & Lack of continuous training \\
8. & Low return on operation \\
9. & Weak enforcement of rules and regulations \\
10. & Lack of support for training and development \\
11. & Poor networking within industry \\
\hline
\end{tabular}

\section{Factors Affecting the Capacity of SMEBCS in Ghana}

In this regard, five out of 27 factors, namely, poor communication structures (mean $=2.92$ ), inadequate access to public contracts (mean $=2.90$ ), structure of the companies (mean $=2.84$ ), unreliable material supply base (mean $=2.78$ ) and high tendering cost (mean $=2.72$ ) were discarded. These factors were discarded because they did not meet the test criterion as stated earlier (i.e. their mean values were lower than the hypothetical mean, $\mu=3.0)$. Hence, 22 of the factors were considered for further analysis. Table 2 presents the mean score of the factors affecting the capacity of SMEBCs in Ghana. 
Table 2. Mean score of the Factors Affecting the Capacity of SMEBCs in Ghana

\begin{tabular}{|c|c|c|c|c|c|}
\hline No. & $\begin{array}{l}\text { Factors Affecting the Capacity } \\
\text { of SMEBCs }\end{array}$ & $N$ & Mean & $\begin{array}{l}\text { Std. } \\
\text { Deviation }\end{array}$ & Rank \\
\hline 1. & $\begin{array}{l}\text { Delay in payments for work } \\
\text { done }\end{array}$ & 80 & 3.94 & 1.083 & 1st \\
\hline 2. & Limited access to credit & 80 & 3.90 & 1.051 & 2nd \\
\hline 3. & High and unstable inflation & 80 & 3.68 & 1.016 & $3 r d$ \\
\hline 4. & $\begin{array}{l}\text { Non-payment of interest on } \\
\text { delayed payments }\end{array}$ & 80 & 3.61 & 1.248 & 4 th \\
\hline 5. & Lack of fair competition & 80 & 3.54 & 1.018 & 5 th \\
\hline 6. & Poor project preparation & 80 & 3.46 & 1.067 & 6th \\
\hline 7. & Change in government policies & 80 & 3.45 & 1.005 & 7th \\
\hline 8. & $\begin{array}{l}\text { Lack of contractual and } \\
\text { managerial skills }\end{array}$ & 80 & 3.44 & 0.898 & 8th \\
\hline 9. & Lack of training opportunities & 80 & 3.42 & 0.925 & 9th \\
\hline 10. & Poor monitoring and control & 80 & 3.41 & 0.910 & 10th \\
\hline 11. & High cost of construction inputs & 80 & 3.40 & 0.866 & 11 th \\
\hline 12 & $\begin{array}{l}\text { Lack of financial management } \\
\text { skills }\end{array}$ & 80 & 3.39 & 1.000 & 12 th \\
\hline 13 & Poor estimation practices & 80 & 3.22 & 0.993 & 13th \\
\hline 14 & Low returns on operations & 80 & 3.19 & 0.943 & 14 th \\
\hline 15 & Lack of material control systems & 80 & 3.18 & 0.897 & 15 th \\
\hline 16 & $\begin{array}{l}\text { Inadequate supportive } \\
\text { institutional arrangements }\end{array}$ & 80 & 3.14 & 0.882 & 16 th \\
\hline 17 & $\begin{array}{l}\text { Long laid down procurement } \\
\text { procedures }\end{array}$ & 80 & 3.12 & 0.905 & 17 th \\
\hline 18 & Lack of technical skills & 80 & 3.11 & 1.043 & 18th \\
\hline 19 & $\begin{array}{l}\text { Non-business-like lifestyle of } \\
\text { contractors }\end{array}$ & 80 & 3.10 & 1.051 & 19th \\
\hline 20 & Lack of entrepreneurial skills & 80 & 3.05 & 0.926 & 20th \\
\hline 21 & $\begin{array}{l}\text { Weak enforcement of contract } \\
\text { rules and regulations }\end{array}$ & 80 & 3.01 & 1.097 & $21 \mathrm{st}$ \\
\hline 22 & $\begin{array}{l}\text { Complicated contract } \\
\text { conditions }\end{array}$ & 80 & 3.00 & 0.955 & 22nd \\
\hline 23 & Poor communication structures & 80 & 2.92 & 0.938 & $23 r d$ \\
\hline 24 & $\begin{array}{l}\text { Inadequate access to public } \\
\text { contracts }\end{array}$ & 80 & 2.90 & 1.026 & 24 th \\
\hline 25 & Structure of the companies & 80 & 2.84 & 1.049 & 25 th \\
\hline 26 & Unreliable material supply base & 80 & 2.78 & 0.981 & 26 th \\
\hline 27 & High tendering costs & 80 & 2.72 & 1.018 & 27 th \\
\hline
\end{tabular}




\section{Factor Analysis}

In this section, the 22 factors affecting the capacity of SMEBCs that were retained in previous section were subjected to further analysis using Principal Component Analysis (PCA). This step made it possible, among other things, for the empirical relationships among the various variables to be statistically manipulated in order to reveal conjectural constructs of the relationships (Neumann and Kreuger, 2003; Field, 2005). Prior to the PCA, Kaiser-Meyer-Olkin (KMO) measure of sample adequacy, KMO test was conducted. The sample adequacy test is passed when the KMO test value is greater than 0.5 (Field, 2005). Consequently, the KMO measure of this study achieved a value of 0.727 , indicating the adequacy of the sample for the factor analysis. Again, the Bartlett's test of sphericity was ascertained to be significant, indicating that the original correlation matrix was not an identity matrix, hence, there are some relationships between the variables that are intended to be included in the analysis (Field, 2005). Indeed, Bartlett's test is highly significant $(p<0.001)$ and therefore factor analysis is appropriate (Field, 2005; Ahadzie, 2007). Table 3 presents both the KMO and Bartlett/s test values.

Table 3. KMO and Bartlett/s Test: Factors Affecting the Capacity of SMEBCs

\begin{tabular}{|c|c|c|}
\hline \multicolumn{2}{|c|}{ Kaiser-Meyer-Olkin Measure of Sampling Adequacy } & \multirow{2}{*}{$\frac{0.727}{670.569}$} \\
\hline Bartlett/s Test of Sphericity & Approx. chi-square & \\
\hline & $d f$ & 276 \\
\hline & Sig. & 0.000 \\
\hline
\end{tabular}

After establishing the sample adequacy of the data and whether or not there exist some relationships among the variables to be included in the analysis, PCA (with Varimax rotation) was conducted. In Table 5, the rotated component matrix indicates that 14 out of the original 22 variables could be the underlying themes of the four principal components (using a cut-off point of 0.50 ). It is to be noted that in an earlier rotation 2 out of the 22 variables vis-à-vis: poor project preparation and lack of material control systems loaded onto two factors which made the interpretation of the findings rather messy. Subsequently, these variables were deleted and the PCA re-ran. Thus, the findings presented in Table 5, on which the discussion is based, emerged after the second round of running the factor analysis. In the second round of the PCA, four principal components with eigenvalues greater than 1, in line with the latent root criterion on the number of principal components were extracted (Field, 2005; Ahadzie, 2007). The initial eigenvalues indicate that if all the factors are ranked, Principal Component 1 accounts for $22.228 \%$ of the variance, while Principal Component 2 accounts for $11.511 \%$ of the variance. In addition, Principal Components 3 and 4 account for $8.868 \%$ and $8.297 \%$ respectively. In all, the four identified principal components account for $50.905 \%$ of the total variance explained (as shown in Table 4). 


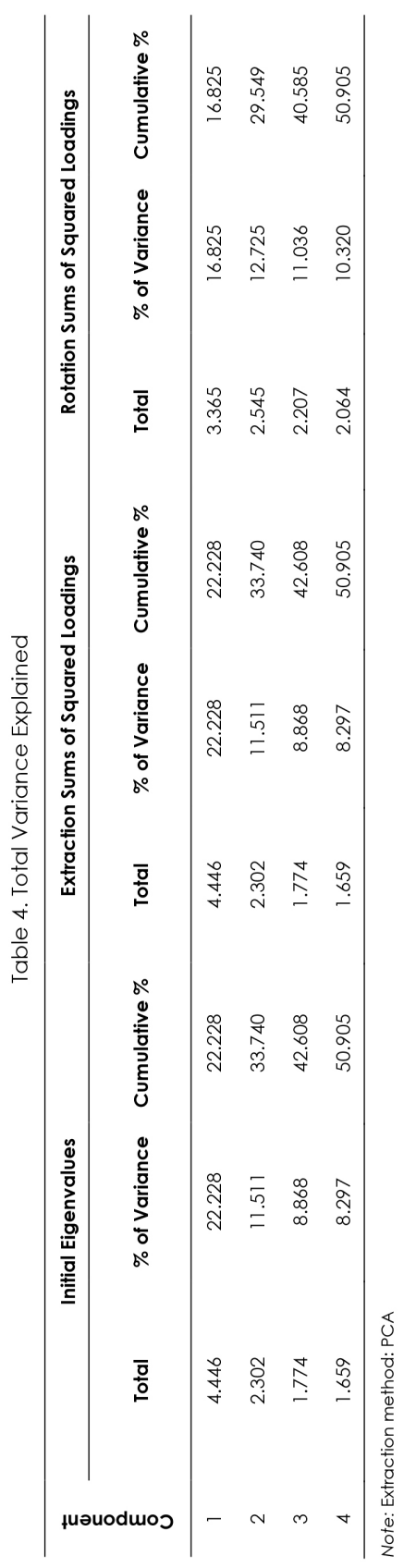




\section{DISCUSSION}

Based on the PCA and critical examination of inherent relationships among the various factors identified, the various components were named (Table 5). The names of principal components were formed based on the factors with the highest loadings and the understanding of the relevance of these factors in the context of the study.

Table 5. Rotated Component Matrix ${ }^{a}$

\begin{tabular}{|c|c|c|c|c|}
\hline \multirow[b]{2}{*}{$\begin{array}{l}\text { Factors Affecting the Capacity } \\
\text { of SMEBCs }\end{array}$} & \multicolumn{4}{|c|}{ Component } \\
\hline & $\begin{array}{l}\text { Technical and } \\
\text { Managerial } \\
\text { Related Factors }\end{array}$ & $\begin{array}{l}\text { Procurement } \\
\text { Related } \\
\text { Factors }\end{array}$ & $\begin{array}{l}\text { Financial } \\
\text { Related } \\
\text { Factors }\end{array}$ & $\begin{array}{l}\text { Project } \\
\text { Related } \\
\text { Factors }\end{array}$ \\
\hline Lack of entrepreneurial skills & 0.695 & & & \\
\hline Lack of technical skills & 0.678 & & & \\
\hline $\begin{array}{l}\text { Lack of contractual and } \\
\text { managerial skills }\end{array}$ & 0.665 & & & \\
\hline Lack of financial management skills & 0.663 & & & \\
\hline $\begin{array}{l}\text { Inadequate supportive institutional } \\
\text { arrangements }\end{array}$ & 0.580 & & & \\
\hline Lack of training opportunities & 0.561 & & & \\
\hline $\begin{array}{l}\text { Weak enforcement of contract } \\
\text { rules and regulations }\end{array}$ & & 0.747 & & \\
\hline $\begin{array}{l}\text { Non-payment of interest on } \\
\text { delayed payments }\end{array}$ & & 0.654 & & \\
\hline Lack of fair competition & & 0.568 & & \\
\hline Limited access to credit & & & 0.802 & \\
\hline High cost of construction inputs & & & 0.763 & \\
\hline Delay in payments for work done & & & 0.635 & \\
\hline Poor estimation practices & & & & 0.780 \\
\hline Poor monitoring and control & & & & 0.736 \\
\hline
\end{tabular}

Notes: Extraction method: PCA; Rotation method: Varimax with Kaiser normalisation; a. Rotation converged in six iterations.

The various principal components with their respective factor loadings (indicated in brackets) have been presented and discussed as following:

\section{Principal Component 1: Technical and Managerial Related Factors}

Six factors loaded were onto Principal Component 1. These are lack of entrepreneurial skills (0.695), lack of technical skills (0.678), lack of contractual and managerial skills (0.665), lack of financial management skills (0.663), inadequate supportive institutional arrangements (0.580) and lack of training opportunities (0.561) (as shown 
in Table 5). The underlying themes that were loaded onto this principal component are mainly related to technical and managerial factors. Literature has revealed that most of the SMEBCs operate a personalised style of management without due regard to effective modern management practices and recruitment methods (Amoah, Ahadzie and Danso, 2011). This may cause them to recruit personnel who do not have the requisite technical and managerial skills. More so, the findings have revealed that there are inadequate supportive institutional arrangements and this has accounted for the low capacity of the indigenous construction firms, particularly SMEBCs. For this reason, lots of researchers and some contractors have called for the formation of an agency that will help address issues pertaining to the development of the Ghanaian construction industry (Ahadzie, 2009; Gyadu-Asiedu, 2009).

\section{Principal Component 2: Procurement Related Factors}

The following factors loaded onto this principal component: weak enforcement of contract rules and regulations (0.747), non-payment of interest on delayed payments (0.654) and lack of fair competition (0.568) (as shown in Table 5). The various factors loaded onto this principal component go to affirm the discrepancies in the Ghanaian public procurement that affect the capacity of contractors observed from literature (Anvuur, Kumaraswamy and Male, 2006; Laryea, 2010; Donkor, 2011; Kheni, 2008). The literature review and semi-structured interview suggest that there is lack of fair competition, for instance in the award of contracts, where contracts are awarded to contractors who have political affiliations and not on meritorious grounds (Donkor, 2011). Indeed, one of the interviewees decried how pretentious the Ghanaian public procurement is, where rules are only pretended to be followed. These lapses go a long way to pollute the business environment within which these SMEBCs operate and hence, stifle their development.

\section{Principal Component 3: Financial Related Factors}

The following factors emerged: limited access to credit (0.802), high cost of construction inputs (0.763) and delay in payment for work done (0.635) (as shown in Table 5). The various factors loaded on this component go directly or indirectly to affect the financial capacity of SMEBCs in Ghana. This tends to corroborate the assertion that finance is a constraining factor to contractor development (Cook and Nixson, 2000). Limited access to credit for instance, has been identified as a major factor that affect the financial capacity of SMEBCs as most of these contractors face a raft of challenges in accessing credits from banks (Cook and Nixson, 2000; Badu and Owusu-Manu, 2010). The situation gets exacerbated when contractors/ capital gets eroded by delays in payment for work done, which has characterised most government projects (Eyiah, 2003). Indeed, one of the interviewees asserted "contractor capacity has been drastically eroded due to delay in payment of work done. Indeed, in some instances, it can take three to four years before a contractor is paid for work done". This goes in line with literature where delay in payment for work done has been identified as a factor that affects the capacity of contractors in Ghana and other parts of Africa (Amoah, Ahadzie and Danso, 2011; Laryea, 2010; Ofori, 2000; Bakar et al., 2012). 


\section{Principal Component 4: Project Related Factors}

The following factors emerged: poor estimation practices (0.780) and poor monitoring and control (0.736) (as shown in Table 5). According to Donkor (2011), these factors contribute to the failure of SME construction firms in Ghana. These factors are mainly associated with the estimation practices of the SMEBCs and how they monitor the resources available to them. It has been revealed in research that small firms do not put into considerations the controlling of equipment cost and usage and employee's benefits and compensations which go a long way to affect their capacity (Donkor, 2011).

\section{CONCLUSION}

Capacity of SME building construction firms in developing countries remains imperative especially as these SMEs serve as economic backbone worldwide. In addition, it has been touted that SMEs in developing countries are the engine for growth for various economic transformation. Thus, the current study revealed significant factors that affect the capacity of SME building construction firms in Ghana. These are broadly clustered as technical and managerial factors, procurement related factors, financial related factors and project related factors. Furthermore, conscious efforts should be made by government to address the issues that have been raised in this paper, to facilitate building of capacity of the SME construction firms in the country. It is recommended that further studies should be carried on by ascertaining the impacts of the various factors that affect the capacity of the SME building construction firms. In addition, strategies for building the capacities of these SME building construction firms in Ghana can be researched into. Lastly, policy makers should increase the capacity of SMEBCs in Ghana through continuing professional development for the various professionals working under the various infrastructures oriented ministries.

\section{REFERENCES}

Agyepong, A.S. (2012). Are contractor classifications in Ghana accurate? The Quantity Surveyor: An Official Magazine of the Quantity Surveying Division of the Ghana Institution of Surveyors, No. 1.

Ahadzie, D.K. (2009). Ghanaweb. Available at: http://www.ghanaweb.com/ GhanaHomePage/NewsArchive/artikel.php?ID=170462 [Accessed 10 February 2014].

- (2007). A model for predicting the performance of project managers at the construction phase of the mass house building projects. PhD diss. University of Wolverhampton.

Ahiaga-Dagbui, D.D., Fugar, F.D.K., McCarter, J.W. and Adinyira, E. (2011). Potential risks to international joint ventures in developing economies: The Ghanaian construction industry experience. In B.O. Uwakweh (ed.), Proceedings of the CIB W107 Conference on Innovation and Sustainable Construction in Developing Countries. Hanoi: Construction Publishing House. 
Amoah, P., Ahadzie, D.K. and Danso, A. (2011). The factors affecting construction performance in Ghana: The perspective of small-scale building contractors. The Ghana Surveyor, 4(1): 41-48.

Ampadu-Asiamah, A.D. and Ampadu-Asiamah, O.K. (2013). Management of government funded construction projects in Ghana: Stakeholders' perspective of causes of delays in construction of public buildings. Developing Country Studies, 3(12): 149-156.

Anaman, K.A. and Osei-Amponsah, C. (2007). Analysis of the causality links between the growth of the construction industry and the growth of the macro-economy in Ghana. Construction Management and Economics, 25(9): 951-961. https:// doi.org/10.1080/01446190701411208.

Anvuur, A., Kumaraswamy, M. and Male, S. (2006). Taking forward public procurement reforms in Ghana. Paper presented at the International Council for Research and Innovation in Building and Construction (CIB) W107 Construction in Developing Countries International Symposium. Construction in Developing Economies: New Issues and Challenges.. Santiago, Chile, 18-20 January.

Ayarkwa, J., Dansoh, A. and Amoah, P. (2010). Barriers to implementation of EMS in construction industry in Ghana. International Journal of Engineering Science, 2(4): $37-45$.

Badu, E. and Owusu-Manu, D. (2010). Improving access to construction finance in Ghana. The Journal of Business and Enterprise Development, School of Business, 2: $111-128$.

Badu, E., Edwards, D.J. and Owusu-Manu, D. (2012). Trade credit and supply chain delivery in the Ghanaian construction industry: Analysis of vendor interactions with small to medium enterprises. Journal of Engineering, Design and Technology, 10(3): 360-379. https://doi.org/10.1108/17260531211274729.

Bakar, A.H.A., Tabassi, A.A., Razak, A.A. and Yusof, M.N. (2012). Key factors contributing to growth of construction companies: A Malaysian experience. World Applied Sciences Journal, 19(9): 1295-1304.

Cook, P. and Nixson, F. (2000). Finance and Small and Medium-Sized Enterprise Development. Manchester: Institute for Development Policy and Management, University of Manchester.

Danso, F.O. (2010). Occupational health and safety issues involving casual workers on building construction sites in Ghana, a Kumasi study. MSc diss. Kwame Nkrumah University of Science and Technology (KNUST).

Donkor, S. (2011). Determinants of business failure: The perspective of SME building contractors in Ghanaian construction industry. MSc diss. Kwame Nkrumah University of Science and Technology (KNUST).

Egbu, C.O. (2000). Knowledge management in construction SMEs: Coping with the issues of structure. In A. Akintoye (ed.), Proceedings of the 16th Annual ARCOM Conference. Belfast: Association of Researchers in Construction Management (ARCOM).

Enemark, S. (2003). Understanding the concept of capacity building and the nature of land administration systems. Paper presented at the International Federation of Surveyors (FIG) Working Week. Paris, 13-17 April.

Eyiah, A.K. (2003). Construction bank in a developing country: The way forward. In D.J. Greenwood (ed.), Proceedings of the 19th Annual ARCOM Conference. Belfast: Association of Researchers in Construction Management (ARCOM), 329-335. 
Eyiah, A.K and Cook, P. (2003). Financing small and medium scale contractors in developing countries: A Ghana case. Construction Management and Economics, 21 (4): 357-367. https://doi.org/10.1080/0144619032000111241.

Field, A. (2005). Discovering Statistics Using SPSS. 2nd Ed. London: Sage Publications.

Fugar, F.D. and Agyakwah-Baah, A.B. (2010). Delays in building construction projects in Ghana. Australasian Journal of Construction Economics and Building, 10(1/2): 103-116. https://doi.org/10.5130/ajceb.v10i1-2.1592.

Govender, J.N. and Watermeyer, R.B. (2000). Potential Procurement Strategies for Construction Industry Development in the SADC Region: Procurement Strategies in SADC Region. Pretoria: Department of Public Works.

Gyadu-Asiedu, W. (2009). Assessing construction project performance in Ghana: Modelling practitioners/and clients/perspectives. PhD diss. Technology University of Eindhoven.

Kheni, N.A. (2008). Impact of health and safety management on safety performance of small and medium-sized construction businesses in Ghana. PhD diss. Loughborough University.

Komu, N.S., Kikwasi, G.J. and Thwala, W.D. (2012). Assessment of management contracting procurement system towards enhancing capacity building for small and medium contractors in Tanzania. In G. Nani, R.K. Nkum, E. Awere, E. Kissi and E. Bamfo-Agyei (eds.), Proceedings of the 1st Applied Research Conference in Africa (ARCA) Conference. Elmina, Ghana: ARCA.

Kululanga, G. (2012). Capacity building of construction industries in SubSaharan developing countries: A case for Malawi. Engineering, Construction and Architectural Management, 19(1): 86-100. https://doi. org/10.1108/09699981211192580.

Laryea, S. (2010). Challenges and opportunities facing contractors in Ghana. In S. Laryea, R. Leiringer and W. Hughes (eds.), Proceedings of the West Africa Built Environment Research (WABER) Conference. Reading, UK: WABER, 215-226.

Morgan, P. (2006). The Concept of Capacity. Maastricht, The Netherlands: European Centre for Development Policy Management, 1-19.

Neumann, W.L. and Kreuger, L.W. (2003). Social Work Research Methods: Qualitative and Quantitative Applications. Boston: Allyn and Bacon.

Ofori, G. (2012). Developing the Construction Industry in Ghana: The Case for a Central Agency. Singapore: Singapore University Press.

. (2000). Challenges of construction industries in developing countries: Lessons from various countries. In 2nd International Conference on Construction in Developing Countries: Challenges Facing the Construction Industry in Developing Countries. Delft, The Netherlands: International Council for Research and Innovation in Building and Construction (CIB), 15-17.

Thwala, W.D. and Phaladi, M.J. (2009). An exploratory study of problems facing emerging contractors in the North West province of South Africa. Proceedings: The Fourth Built Environment Conference. Bellville, South Africa: Association of Schools of Construction of Southern Africa (ASOCSA).

United Nations Educational, Scientific and Cultural Organization (UNESCO) (2006). Capacity building. In Guide Book for Planning Education in Emergencies and Reconstruction. Paris: International Institute for Educational Planning, 1-10.

van Egmond, E. and Erkelens, P. (2007). Technology and knowledge transfer for capability building in the Ghanaian construction industry. In CIB World Building Congress. Delft, The Netherlands: CIB, 1393-1405. 